류재춘 · 김종훈' - 이상회 ${ }^{*}$

군산대학교 화학과

‘천쭈대학교 환겅과학기술학과

(2003. 11.3 칩수)

\title{
Molecularly Imprinted Polymer for Adsorption of Bisphenol A
}

\author{
Jac Chun Ryu, Jong-Hun K'im , and Sang Hee Lee*

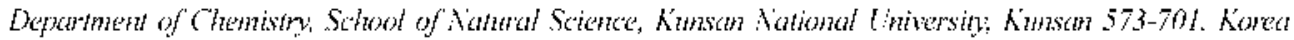

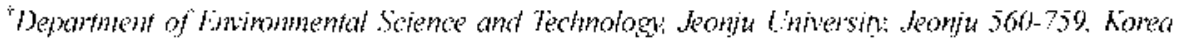

(Riocived November 3. 2003)

주제어: 비스페녹 $\mathrm{A}$. 고상 추출법. 분자각인 J'분자

Keywords: Bisphenol A. Solid Phase I:xtraction. Molecular imprinting Polymer

Bisphenol $\mathrm{A}(\mathrm{BP} \mathrm{P})$ 는 에폭시 수지와 본러카보녜이트 풀라스턱의 제조에 쓰이는 단량체이나. 이 풀라스턱은 믾은 시푹과 음료의 픈장제로 사용되는녜, 수지는 캑용 기. 녕뚜껌. 상수관 같은 금속제눈을 코팅학는: 락커 (lacquer)론 이용뇌며 치과에서 사용뇌는 및및 정합체도 $\mathrm{BPA}$ 를 포핚하고 있다. 1.3 한편. BPA는 strogenic 네분 비피?란물질(Iindocrine I)isruptors) ${ }^{+5}$ 로 알려져 있어 식

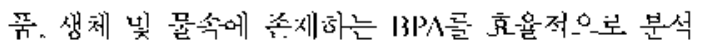

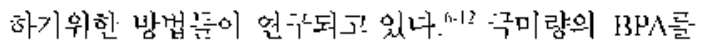
첨량적으로 분선하기 위해서는 먼저 효율석으론 능혹 하는: 과청이 횔수적이다. 유기용매를 사용하여 반복적 으로 후출(liquid-liquid extraction)하고 낭 축하는: 방법 은 많은 양의 육기 용대와 시간이 소오되므도 카드러지

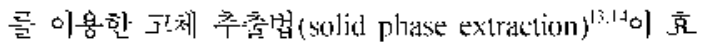
울적이며 특히 자동화된 모니터링을 위해 풜 오하나. $\mathrm{BPA}$ 는: 비교적 극성이 콘 관계로 읶반적인 합착하느러

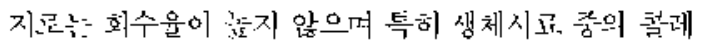
스테롤이나 인지질 등이 핚께 흡착뇌어 청향분석에 어 러운을 주기 때문에 $13 \mathrm{P} /$ 를 보다 선댁적으로 강하게 홉 척함 수 있는 카트리지가 오-다됙나. 따라서 변 연구에 서는 $\mathrm{BPA}$ 에 내힌 홉착능러이 우수한 카트러지의 개발 은 위하여 분차각인 고분찰를 합섬하고사 한다.<smiles>CC(C)(c1ccc(O)cc1)c1ccc(O)cc1</smiles>

fig. I. Bisphenol $N(B P A)$.

분자각인 고분자 설계 및 합성. 분자 각인(moleculaㅈ imprinting)은 합성 5 '분자에 인시자러(recognition site) 를 난돓기 위한 낭법이나. 분자 가인ㄴ을 위하여 많은 경 우 카르부식기와 아민기간의 ionic 싱호삭용운 이용하

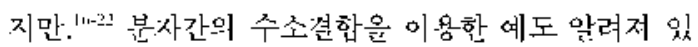
다.2. 본 연구에서는 소수성(hydrophobic) 상호작염 및

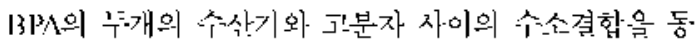
시에 이용하거자 한다. 이러한 전락을 Sheme l에 $1=$ 식적으로 나타내었나.

고분자의 단향체 룬서 소수성이며 교차연견 고분자의 곤격운 유지할 수 있논- divinyltenzeno(DVB. $15.4 \mathrm{mmol}$ ) 은 사용하었고 아울러 BPA와 수소견함울 할 수 있눈: 화함물인 A-vinylpyrolidone(VVP. 13.2 mmol)을 사용 하었나. 즈형 분자 손체 하에서 공중핚시킴으로서 $\mathbf{B}$ 아. 긴은 소수성 줃머니 안에 주형분자가 프퇵된 과차연격 공흥함체(crosslinked copolymer)를 얻고사 하었다. 포 


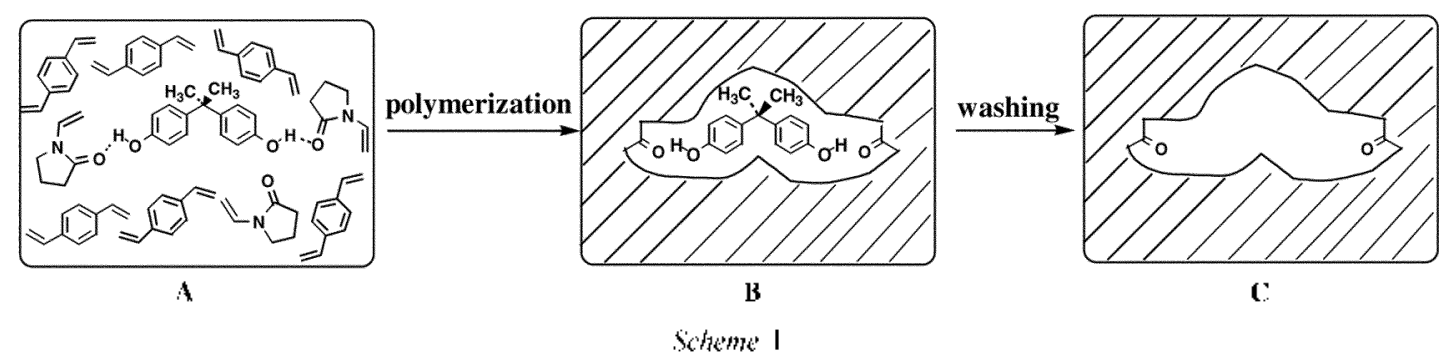

Fable I. Conditions of polymerization

\begin{tabular}{|c|c|c|c|c|c|c|c|}
\hline polyme & & II & III & IV & V & & VII \\
\hline Polymerization & \multicolumn{4}{|c|}{ Suspension polymerization" } & \multicolumn{3}{|c|}{ Solution polymerization" } \\
\hline Template & & 3 & 3 & 4 & & 3 & 4 \\
\hline Porogenic solvent $(\mathrm{ee}))^{\circ}$ & Loluene $(2.4)$ & toluene $(2.4)$ & toluene $(1.2)$ & toluene $(2.4)$ & loluene $(1.8)$ & $\mathrm{CH}:(\mathrm{Cl}:(1.8)$ & toluene (1.8) \\
\hline
\end{tabular}

'polymerization was performed at $70^{\circ} \mathrm{C}$ ' for $20 \mathrm{~h}$, b) polymerization was performed at it for $15 \mathrm{~h}$ under $(\mathrm{V} V$ light. c) based on the amoumt of monomers ( $[\mathrm{V} \vee \mathrm{B}+\mathrm{NVP})$.

Tahle 2. Recovery efficiency and composition of polymers

\begin{tabular}{|c|c|c|c|c|c|c|c|c|}
\hline Polymer & & & II & III & IV & V & $V[$ & VII \\
\hline \multirow[t]{2}{*}{ Composition (mmole $\%)^{3}$} & [) & 74.3 & 73.2 & 69.5 & 66.0 & 91.7 & 96.4 & 91.8 \\
\hline & VVI & 25.7 & 26.8 & 30.5 & 34.0 & 8.3 & 3.6 & 8.2 \\
\hline Recovery efficiency $(\%)$ & & 7.1 & 15.5 & 18.1 & 17.4 & 6.8 & 20.7 & 66.5 \\
\hline
\end{tabular}

Jetermined by elemental analysis of polymers.

획됙 주형분자를 - 유기용매로 씻어 제거함-으로서 고분 차 C를 얻었다. $\mathrm{C}_{1}^{2}$ : 소수성 뚜머니 안에 BPA의 수산 기 $(-\mathrm{OH})$ 가 수소결합을 한 수 있는 차르녀닐기 $(\mathrm{C}=\mathrm{O})$ 를 적당한 위지에 갖고 있다. 마라서 크기와 보양이 석당 한 고분자의 소수성 주머니와 13PN의 소수성 범분간의 닌녜고밬스 인력 그러고 수산기와 카고보넉기간의 수 소격합으로 인하여 고분자 $\mathrm{C}$ 는 $\mathrm{BP}$ 솨와 매웅 안정한 칙. 눌을 형성할 수 있도록 하였다.

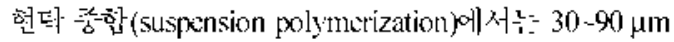
크기의 구형 (granular bead) 중합체를 얻울 수 있어 -프 내로 카드러지의 그정상응로 사용하었나, 유기용매로

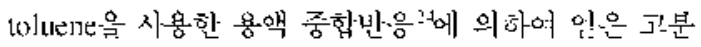
자는 막자사발로 질게 북-수고 데탄올에서 낭치하여 북 유하는: 디세입차늘 제기하였다. 침선된 입차들 총 니부 콘 인사는 $90 \mu \mathrm{m}$ 의 sicve를 이용해 제기하고 $30-90 \mu \mathrm{m}$ 의 식경을 갖는 입사늘 얻어 사용하였다. 충합 반응 즈 건을 Fable 1에 오약하었나. 각 닌응초건에서 잃어진! 고분자에 한유되어 있는 단량체의 초성을 뉜소분석에 근거하여 격정하었고 이를 $\mathrm{Table}$ 2에 나타내었다. 중 합반응에 사용한 두 단량체의 비율은 포두 같았지만
중핚반응의 초건 닟 사용힌 용매에 따라 얻어신 고분 차에 포함된 두 단량체의 조성에는: 큰 차이를 보였다.

주혐의 설계 및 합성. 본 연구에서 BI'A를 효과적으 로 인식하기 위한 분자각인 고분자를 한성하기 위해서 사용해야하는 이상적인 줗형은 $\mathrm{BP} \mathrm{P}$ 자체라 핯 수 있 나. 그러나 phenol 계통은 라녀칼 중합닌응에서 중합 저 해제로 작용하므로 $13 \mathrm{P} \wedge$ 를 주경으을 사용하는 것은 분

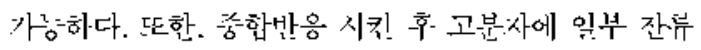
할 수 있녹 $\mathrm{BPA}$ 는 싱항분석 할 때 매우 큰 오차를 유 발한 수 도 있다. 마라서 BPA를 데신할 수 있는 주형 분자로는 수산기롤 아띤기로 치환한 주혐 2가 수소결 학을 핮 수 있어 먼저 챙각핮 숫 있으나 아낀 여시 라 너칼 중합닌응을 저해하여 중합만응이 일어나지 않았 은 뿐만 아네라 화학적으론 안싱섬이 낮아 사영할 수가 없었다. 마라서 본 연구에서는 분사의 크기가 커.지긴 하지만 분사 신체의 꼬양에는 콘 견화가 없고 수소결합 을 할 수 있는 주형 3을 사용하였나. 주혐 3을 단량체 (I)VI3 닟 VVP)아 혼함한 후 중합반응 시킬 때 $70180^{\circ} \mathrm{C}$ 의 온-1에에서는 문제가 없었으나 상온에서 중학반응 시 키고사 할 때는 용해도가 낮아 규ㅁㅣㅣ한 용액이 만들어지 
<smiles>CC(C)(c1ccc(O)cc1)c1ccc(O)cc1</smiles>

1

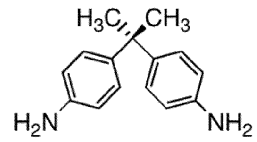

2

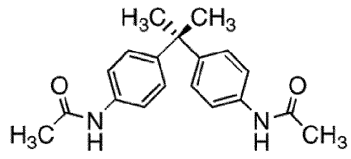

3

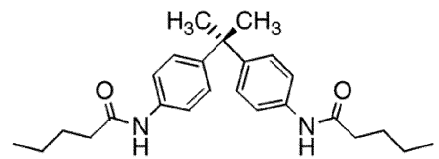

4

Fig. 2. Stucture of the templates.

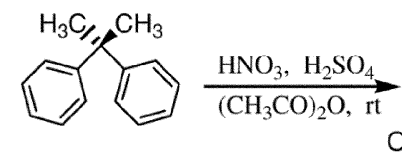

5

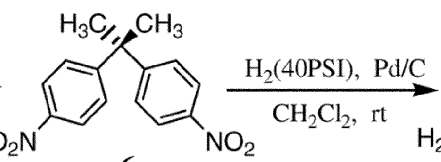

6
住

2

Sheme 2

지 않았다. 마라서 저온 중합반응에서는: 분자의 유연성 은 증가시켜 용해도 논제를 해견하기 위하여 뚜형 4 늘 사용하었다.

주형 3 닟 4의 합성과정을 Sheme 2에 나타내었다. 5 로부터 para 위치에 신댁적으을 nilralion시킬 수 있었 으며. 네노론기는: $\mathrm{PdC}$ 축매 하에서 수소화 반응시켜 아민으론 천환하여 2를 얻었다. 아민 2는 acctyl chlorido 또는 valuroyll chloride와 반응시킨으론서 3 및 4 를 각 각 언을 수 있었나.

BPA 회수올 측정, 각 고분자의 $\mathrm{BP}$ 세 내한 회:수율 촉정격롸를 fable 2에 나타내었나. 여기서 회수율은 $\mathrm{BPA}(1.0 \mathrm{ng} / \mathrm{ml})$ 를 핚유한 수용액 $300 \mathrm{ml}$ 를 고분사 $1.0 \mathrm{~g}$ 에 통과시첬은 대 고분사에 훕착된 $\mathrm{BP}$ 의 양을 \%를 나
타댄 값이다. 고분-자에 흡착된 $\mathrm{BJ}$ 'A를 유기영매론 왕출 시켜 고 양은 $\mathrm{GClMS}$ 를 싱량하여 견싱하였다." 한펵 $\mathrm{BP} / \mathrm{N}$ 와의 친화려을 높이기 위하여 주형을 사용한 경-움 (II, III, IV, VI 닟 VII)가 주형을 사용하지 않은 J!분 자 (I 닟 $\mathrm{V}$ )에 비하여 $13 \mathrm{P} /$ 에 대한 회수월이 헌저하게 증가하였다. 이러한 분차각인 효과년 현타중합에서버다 용액중합반응에서 디욱 효과석이었는:데. 이는 Fig. 3에 나타낸 바와 같이 설명할 수 있다. 헌타둥ㅇ합반음(a)에서 는 물을 시용하므로 친수성기를 갂는 주혐분자와 .VVP 단량체가 파면의 물과 각각 회합을 함으로서 주형분자 와 VVP간의 회합의 정 $5:$ 가 낮아지는 반면, 봉액중합 (b)에서는: 꽆이 없으므롣 두 친수성기간의 회합이 버다 용이하기 때년-으론 축측된다.

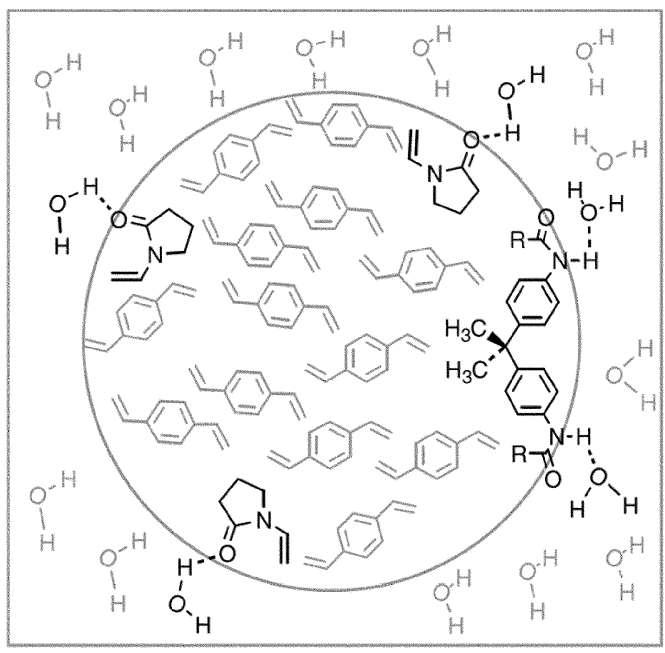

(a) Suspension polymerization

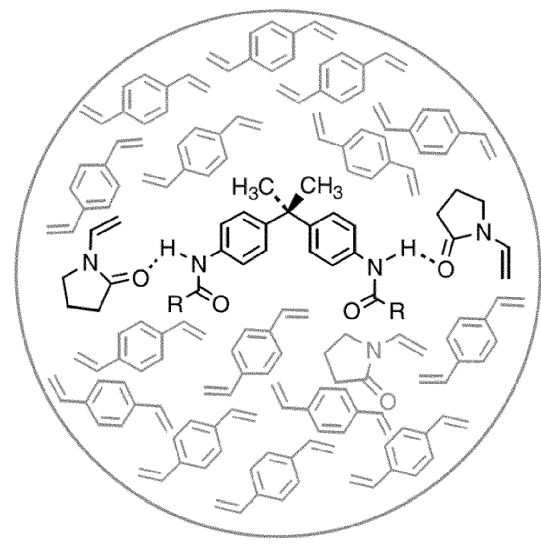

(b) Solution polymerization

Fig. 3. Interaction between template and monomer: 


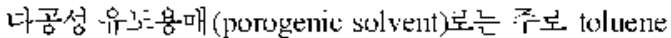
을 사용하였는녜 사용량을 달리하여 합성한 고분자(11 와 III)의 회수율 측정결과는: 콘 차이를 보이지 않았다. 상온에서 충합반응 치키는 겅우(고분사 VI)에는 추힝 분사 3이 tolutnw에 녹지 않았으므로 용매를 chloroform 으로 마구었는례. 그에 따다 회수알이 주형분자 늘 사 용하고 용매로 toluene을 사용한 VII보나 13PA 회숙을 이 코게 낮아젔는뎨. 이러한 차이는 주형의 구쏘의 차 이너다는 사욤한 욤매 및 고분사에 함유된 NVP의 함 랑의 차이에서 기인 한 섯으로 보인다. 만약 친수섬인 NVP를 적께 사용하년 고분사에 눌이 침누하기카 어려 위져 결과적으노 수용액중의 환경호ㄴㅡㅡ논 물질이 거분

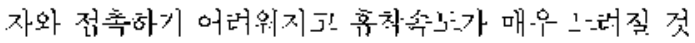
이나. 또한 수소결합자리가 북족하여 홈척능러이 저하 됙 것이다. 반대로 니부 딶이 사용하년 소수성 환겅호 르몬 눌신과의 소수섬 싱호삭용이 약화뇌어 역시 흡착 능력이 저하될 섯이다. 이러한 첨은 고려하여 NVT 및 주형분자의 사용량 굼의 최적화에 내한 연구가 수행 중 이나.

\section{인 용 문 헌}

1. Borotons, J. A. Olea-Serrano, M. Г.: Villaloobos. M.:

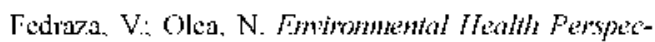
the 1995, 103,608

2. Kawamura, Y.:Inoue, K:; Nakazawa, II.; Yamada, T.: Maitani, T. J. Food Higien. Soc. Japon. 2001, $12,13$.

3. Munguia-I.opez. Г.. M.: Soto-Valder. I1. J. Igricultwral Ford (Th' 2001, 49, 3666 .

4. Krishunan, A. V: Starhis, P.: Permuth, S. F.: Tokes, I.:; Feldman, D. Fndocrinology 1993, 132, 3.

5. Brotons, I. A.; Olca-Sctrano, M. F.: Villalobos, M.; l'edreza. V.: Olea. N. Emirm. Heath Perspect. 1995. 105. 70 .

6. Sajiki. I. J. Chromatogr: B. 2001. 755. 9.

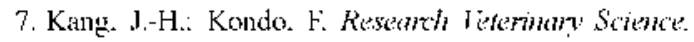
2002. 73.177.

8. Biles. J. E.: Meneal. T. 1:: Beggley: T. H. J. Agriothturat Food Chem. 1997. 45. 4697 .

9. Horie. M.: Yoshida. 1.: Ishii. R.: Nakazawa. H. Bumsehi Kugakn 1999. 48. 579).

10. Imanaka. M.: Sasaki. K.: Nemoto. S.: Ueda. E.: Murakami. E.: Miyata. d.: Tonogai. Y. J. Food Hygien. Soc. Japan. 2001. +2.71 .

11. Inouc, K.: Kato, K.: Yoshimura, Y:: Makino, T: Naka7.0w: H. J. (hormotogn B, 2000, 749, 17
12. P'erderson. S. N.: Lindholst. C. J. Chomatogr. A, 1949. 864. 17.

13. Hankemeier. 'I:: van Leewen. S, S'. J.: Vreuls. R, I. J.: Brinkman. U. A.Th. J. Chromatogh .A. 1998. 811. 117.

14. Vema. K. K.: Louter. A. H. H.: Jain. A.: l'oeurull. E.: Vrucls. J. J.: Brinktnan. U. A. Th. Chomotographia, 1997. 4f. 372.

15. Sellergren. B. Trends inal (hem. 1997, 16, 310

16. Shea. K. I. Trends Polmm Sici. 1994, 2. 166.

17. Wulti. G. ingew (Them. Int Ed Engl. 1995, 34. 1812.

18. Vidyasankar. S. Amold. F. II. (um Opin Biotecimol. 1995. 6. 218

19. Stcinkc. J.: Sherrington, D. C.: Dutnkin. I. R. idv Pohm Sici. 1995, 123, 81

20. I Iaupt. K.: Mosbach, K. Truhds Biotechnol. 1998, 16. 468.

21. Takcuchi. T.: H Jaginaka. I. J. (Twomatogr: B 1998, 728, I.

22. Mayes. A. G.: Mosbach. K. Thends . Anal. Chem. 1947. 16. 321 .

23. Yu. C:: Mosbacli. K. J. Org. Chem. 1997. 62.4057.

24. 분자 각인 고분자 Vllo의 합성(solutionpolymeriatikn). Borosilicute glass 시험관에 주형 $+(454.5 \mathrm{mg} .1 .152$

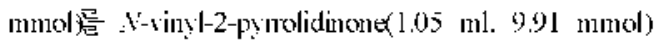
에 가역하어 국인 후- divinylbencene(DVB-80. 80\% $2.04 \mathrm{ml} .11 .52 \mathrm{mmol})$. toluene $(2.2 \mathrm{ml})$ - -1 리고 AIBN (58.6 m․ㅜㅇ. $0.35 \mathrm{mmol}$ 를 가하였다. 혼합 숑액을 어 파 하어 소량의 녹시 읺은 붑보을 제기한 후 건조눤 진소로 5 북간 purceㅏ하였다. 시험관을 나개로 잘 먁은 후 상온에 서 15 시간 동안 UVV $\operatorname{lamp}(365 \mathrm{~mm})$ 로 중합반응을 하였 다. 싱성딘 고분자를 막자사발을 이셩-하어 입지의 커기가

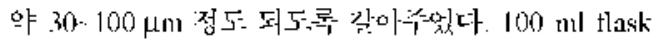
에 갂아직! 고분자와 CII $\mathrm{CHI}(50 \mathrm{ml})$ 을 넣고 10 시간 동 안 교반한 후 10 분간 방치하였다. 얻어직 칚 신물을 glass tilter로 어과하고 즘류수외. $\mathrm{CII}_{3} \mathrm{OII}$ 그리고 $\mathrm{Cl}_{2} \mathrm{Cl}_{2}$ 로 충분히 씻어 반응에 참여하지 않은 단랑체들과 축형 을 세거한 후 70 "C에서 20시간 농안 친조하였다. 산

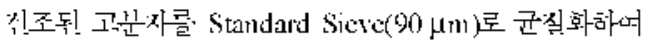
고분자 VII( $\left.1.722 \mathrm{~g}, 67.5^{\circ} \mathrm{o}\right)\left(1.5 \mathrm{~g}, 58.8^{\circ} \mathrm{0}, 90 \mu \mathrm{m}\right)$ 을 백섹 고체로 얻었다. 원소분석: $\mathrm{C}\left(88.83^{\circ} \mathrm{o}\right), \mathrm{HI}\left(8.11^{\circ} \mathrm{o}\right)$.

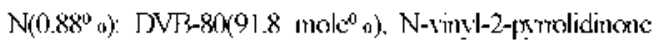
$\left(8.2 \mathrm{molco}_{0}\right)$.

25. 고체 추촐법 (solid-phase extraction methods): 합싱 한 고부잦ㄹㄹㄹ 주사이 컬럽(L95×D12 mm 에 충진시킨. 훅. $10 \mathrm{~m}$ 의 $\mathrm{CH}_{2} \mathrm{Cl}_{2}$ 와 $10 \mathrm{ml}$ 의 메단온 - 긍귱수 $(1: 1)$ 로 가법게 씻어주었다. 여기에 각 $0.01 \mu \mathrm{gm}$ 의 BFA와 네 받표준물진인 antracene-d $101 \mu \mathrm{g} 1$ 을 핚유한 표준영-애 $300 \mathrm{ml}$ 를 분담 $2 \mathrm{ml}$ 의 속노로 동과시 컸다. BPA와

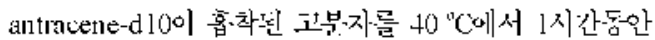
건소시킨 후. $20 \mathrm{ml}$ 의 $\mathrm{CH}_{2} \mathrm{Cl}_{2}$ 로 추훌하여 무수 황산나 트룭으르 건소하고 회전식 긍발기를 이영하어 약 $0.2 \mathrm{ml}$ 로 viak에 농축하였다. 농훅련 시로.를 질소가스르 purge 
학 후 GC-Mass로 분식하였다.

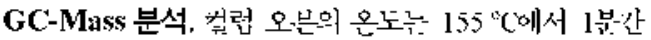

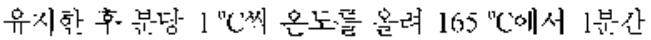
미둔게 하고. 분당 $6^{\circ} \mathrm{C}^{\circ}$ 씩 을려 $200^{\circ} \mathrm{C}$ 에서 1 분간 미문 게 학 다음 가시막으로 분당 $10^{\circ} \mathrm{C}$ 씩 온노를 을려 $300^{\circ} \mathrm{C}$ 에시 변혼꾼석 하었다. 시료는 니세 의-사기를 사
용하어 $1 \mu$ 의 시로를 주입하였고. split ratio는 14 : 1로 하였다. 이당기체 (cwirier gas)는 헬랍(He. 99.99900)기 체를 사용하였고. 유속은 번당 $1 \mathrm{ml}$ 로 존전하어 사영-하 였다. 주입구(injector)와 건훈기(deledor)의 온노느- 각 각 $200^{\circ} \mathrm{C}$ 와 $250^{\circ} \mathrm{C}$ 에서 분시하였다. 